\title{
Agriculturas amazônicas: cultivando plantas, saberes, paisagens e ideias
}

\author{
Pascale de Robert \\ Institut de Recherche pour le Développement
}

Claudia López

Museu Paraense Emílio Goeldi

Estudos antropológicos e em etnociências sobre agriculturas indígenas ou tradicionais tiveram um papel determinante no olhar das sociedades ocidentais sobre a floresta amazônica. Longe de ser um espaço 'virgem', intocado, 'natural', a floresta amazônica é reconhecida como floresta antrópica, na construção da qual os povos indígenas tiveram, e têm, um papel chave. Nessa perspectiva, lembramos, em particular, dos trabalhos de Darrell Posey entre os Kayapó, povo de língua Jê que habita no rio Xingu, e de William Balée entre os Ka'apor, povo de língua Tupi que habita na região do rio Gurupi, como referências essenciais para a temática que nos interessa. Ambos os pesquisadores foram acolhidos no Museu Paraense Emílio Goeldi durante as suas principais pesquisas'. O convite do Editor Científico do Boletim do Museu Paraense Emílio Goeldi. Ciências Humanas para organizarmos o presente dossiê, "Agriculturas Amazônicas", reforça essa 'tradição' científica da instituição, que continua vigente e pode ser observada em outros dossiês temáticos².

Apesar dos fatores de mudança atuais na Amazônia (pressão fundiária, frentes de colonização e de desmatamento, expansão demográfica, urbanização, migrações, articulação ao mercado, entre outros), os sistemas agrícolas tradicionais continuam extremamente eficientes, garantindo, até hoje, a subsistência de uma população crescente e a preservação de um patrimônio cultural e genético cuja importância ainda é pouco reconhecida. Os trabalhos reunidos aqui testemunham a diversidade e a complexidade de tais sistemas agrícolas e evidenciam a importância dos povos indígenas e das populações tradicionais no manejo, na conservação e na construção da biodiversidade e agrobiodiversidade amazônicas. Também procuram discutir os atuais desafios na busca de alternativas sustentáveis capazes de valorizar a multiplicidade de agriculturas amazônicas e avaliar as ferramentas jurídicas, econômicas ou culturais que podem contribuir para valorizar e proteger os conhecimentos tradicionais associados à biodiversidade e agrobiodiversidade. A maioria dos autores privilegiou métodos de trabalho que combinam levantamentos quantitativos e qualitativos, utilizando ferramentas adaptadas de várias disciplinas e desenvolvendo pesquisas de campo na escala das comunidades.

O primeiro artigo nos leva ao mundo sumamente complexo das relações técnicas e simbólicas que os Jodï, povo indígena da Amazônia venezuelana, desenvolvem com o seu entorno vegetal. Após descreverem o 'estado da arte' sobre coletores e cultivadores de florestas tropicais, Stanford Zent e Eglée Zent questionam, e logo derrubam com argumentos etnográficos, analíticos e quantitativos inspirados nos Jodï, diversos preconceitos habitualmente associados aos sistemas de cultivo tradicionais, e mais especificamente indígenas. Com técnicas que variam de acordo com os lugares cultivados na floresta, e também com as prioridades e com a mobilidade dos grupos, os Jodï manejam uma grande diversidade específica e varietal de plantas cultivadas e semidomesticadas. A eficiência do sistema em termos

1 Ver as contribuições em homenagem a Darrell Posey (1947-2001) na sessão Memória deste mesmo número.

2 Mais recentemente, nossos colegas Cristina Adams e Rui Sergio Sereni Murrieta (2008) organizaram um dossiê intitulado "Agricultura de corte e queima e florestas tropicais em um mundo em mudança". 
agroecológicos, de tempo de trabalho, de produção, de segurança alimentícia e de durabilidade, é demonstrada com dados quantitativos acumulados durante vários anos; sua flexibilidade ou capacidade de ajuste permite privilegiar, segundo os lugares e as épocas, os produtos da agricultura, da coleta ou da caça para se alimentar. A complexidade das práticas e dos saberes associados - como escutar o canto noturno da rã woijlodi para decidir a queima - também é apresentada nas suas relações com uma filosofia da vida e nas relações com os outros seres da floresta, que os autores caracterizaram como "predação mística" em trabalhos anteriores. Até então mal categorizados como "agricultores incipientes', os Jodï nos convidam a um olhar radicalmente novo sobre a riqueza, a complexidade e a diversidade das agriculturas amazônicas tradicionais.

Como os Jodï, porém na bacia do médio rio Xingu, no Brasil, os Mebêngôkre-Kayapó cultivam principalmente batata doce, inhame, milho, banana e mandioca nas suas roças novas e antigas, integradas às paisagens de floresta e ao cerrado onde habitam. Mais de 20 anos depois dos trabalhos pioneiros da equipe de Darell Posey ${ }^{3}$, e apesar de fortes mudanças ocasionadas pelo avanço da frente de desmatamento e de colonização agropecuária na região, os Mebêngôkre continuam manejando uma extraordinária diversidade de plantas alimentícias. Em duas aldeias do sul do Pará, Pascale de Robert e colaboradoras estudaram o manejo da agrobiodiversidade das roças (puru), principal espaço, mas não único, reservado às plantas cultivadas. A roça é um lugar-chave no processo de construção territorial, um marcador da história do povo, e a sua organização testemunha a inscrição temporal e espacial na floresta. Os Mebêngôkre, principalmente as mulheres, compartilham uma verdadeira 'paixão' pela diversidade agrícola, cultivando muitas variedades dos principais cultivos. Os mecanismos de aquisição, circulação e conservação da agrobiodiversidade Mebêngôkre são discutidos à luz do conceito de 'beleza' (mex), que celebra a abundância, a diversidade e a vitalidade das trocas e relações sociais com o outro.

Os artigos seguintes dão mais ênfase às práticas e aos conhecimentos associados à planta mais emblemática das agriculturas amazônicas tradicionais: a mandioca. Em 13 comunidades de Reservas de Desenvolvimento Sustentável do Médio Solimões, Deborah Lima e colaboradoras realizaram um estudo detalhado das práticas associadas ao cultivo e das dinâmicas da agrobiodiversidade das 'manivas' em várias escalas espaciais e temporais. Comparando as coleções individuais, familiares e comunitárias, evidenciam uma grande riqueza varietal, caracterizada pela distribuição ampla de poucas variedades (e, portanto, ocorrência localizada da maioria) e explicada, entre outros fatores, por preferências alimentícias, demandas do mercado e características ambientais (terra firme e várzea). Com levantamentos de campo duplicados em dois períodos, as autoras também procuram analisar mudanças diacrônicas na composição das coleções, como o abandono de algumas manivas, associado ou não à cheia de 2009, e o surgimento e a difusão de outras, por exemplo, a 'catombo', hoje apreciada por todos. Os resultados testemunham a importância das trocas locais e regionais e dos processos de experimentação intensa entre os agricultores tradicionais, que demonstram ter uma grande capacidade de inovação e nunca economizam esforços para introduzir, experimentar e adaptar novas variedades e técnicas, em cada geração e há muitas gerações.

Rio acima, no alto Solimões, comunidades das etnias Ticuna e Cocama compartilham o mesmo modelo alimentício regional, baseado em peixe e farinha de mandioca, e um mesmo território, onde participam da construção e transformação das paisagens. No seu estudo, Sandra Noda e colaboradores demonstram a importância de um enfoque metodológico capaz de imbricar diferentes escalas de trabalho, para estudar a diversidade e a complexidade dos sistemas

\footnotetext{
3 Ver, por exemplo, o artigo do Anderson e Posey (1985), publicado também no Boletim do Museu Goeldi.
} 
de cultivo amazônicos. As principais unidades de paisagem são caracterizadas como "arranjos produtivos" e formas de gestão dos recursos naturais específicas da região. Conhecimentos e práticas observados no nível da comunidade ou da roça também são detalhados: categorias locais de vegetação nos ciclos sucessionais; 'receita' de composto orgânico à base de folhas secas, cogumelos e minhocas; organização tradicional do trabalho agrícola; diversidade específica e varietal; entre outros. Os autores também dão atenção especial aos fatores históricos, sociológicos e ecológicos que influenciam a construção das paisagens atuais, organizados em uma "complexa imbricação em constante modificação", assim como ao papel das políticas públicas nas dinâmicas atuais.

Na mesma região, porém do outro lado da fronteira que separa Brasil e Colômbia, Luis Eduardo Acosta e José Zoria abordam as políticas públicas e ferramentas jurídicas elaboradas para proteger os conhecimentos tradicionais. A reflexão é centrada nos direitos de propriedade intelectual em nível internacional e no contexto específico colombiano, detalhando a experiência original de duas comunidades indígenas Ticuna. Por meio de metodologias participativas, discutiram com os Ticuna colombianos a importância e a possível aplicabilidade de modalidades do Direito de Propriedade Intelectual, nesse caso, a marca coletiva e a Indicação Geográfica para a farinha produzida com a mandioca cultivada nas chacras (roças) das comunidades. Os autores consideram a importância dos conhecimentos tradicionais associados à biodiversidade, já que os Ticuna manejam numerosas variedades de Manihot esculenta, enfatizando o lugar central da planta na cosmologia desse povo.

A complexidade do manejo das plantas manifesta-se nos modos de cultivo, mas também na forma de processar as plantas cultivadas destinadas ao consumo. No caso da mandioca amarga, a transformação de uma raiz venenosa em uma farinha 'especial', com sabor, consistência, coloração e aroma apreciados em casa e no mercado, requer um conjunto extremamente elaborado de gestos, técnicas e saberes. Lucia van Velthem e Esther Katz estudaram em detalhe as fases desse processamento praticadas por pequenos agricultores do alto Juruá, uma região caracterizada pelos aportes de diversas ondas migratórias. As autoras cuidaram de analisar as relações com os artefatos utilizados na fabricação do produto, os quais, muitas vezes, são esquecidos nas pesquisas sobre agrobiodiversidade. Além das suas funções utilitárias, e assim como acontece com as plantas cultivadas, os objetos têm a capacidade de 'fabricar' ou 'alimentar' laços sociais. Nas concepções locais, a farinha de qualidade é um produto familiar moldado por múltiplos fatores agroecológicos, socioeconômicos, simbólicos e culturais. Como mostram as autoras, esses aspectos são ignorados pelos comerciantes e pelas instituições governamentais que apenas se preocupam com condições mais higiênicas de produção.

De forma mais ou menos explícita, a questão do manejo das sementes foi abordada em todos os artigos, pelo importantíssimo papel que cumprem na reprodução dos sistemas de cultivo e na conservação da agrobiodiversidade. Ao final do dossiê, Juliana Santilli faz uma análise crítica dos impactos da Lei de Sementes brasileira (10.711/2003) e levanta uma interrogação crucial: a nossa legislação e as políticas públicas atuais têm capacidade para cumprir com os objetivos de proteção da diversidade e da complexidade dos sistemas de cultivo tradicionais? A autora mostra como a Lei de Sementes pode contribuir para agravar os processos de perda de diversidade genética por atender aos interesses e às necessidades do sistema 'formal' de sementes. Espécies de grande valor comercial cultivadas em ambientes homogêneos são protegidas, enquanto as práticas locais de produção, conservação, melhoramento, coleção e intercâmbio de sementes tradicionais são desconsideradas. Tais disfunções podem ser explicadas com a persistência de uma visão evolucionista - aquela que os Jodi ajudam a derrubar -, que pensa o 'progresso' como a imposição de um único modelo agrícola, industrial e produtivista. Mesmo assim, esta última contribuição desse dossiê abre pistas para outras pesquisas e, talvez, para um futuro otimista. 
Para finalizar, entendemos que a complexidade e a diversidade não são privilégios exclusivos das agriculturas amazônicas tradicionais. Longe de se encaixar no 'sistema formal', a maioria dos agricultores da Amazônia, dos espaços tropicais e subtropicais de todo o mundo, e mesmo de países mais impactados pela 'revolução verde', continua preferindo sementes 'da casa' ao guardá-las de uma safra para a seguinte. Podemos pensar que muitos dos sistemas e modos de cultivo atuais valorizam relações privilegiadas, até mesmo afetivas, com as plantas, e que a criatividade dos agricultores tradicionais contribuirá para melhorar técnicas e para conservar a agrobiodiversidade com conhecimento, imaginação e emoção.

\section{REFERÊNCIAS}

ADAMS, Cristina; MURRIETA, Rui Sérgio Sereni. Agricultura de corte e queima e florestas tropicais em um mundo em mudança. Boletim do Museu Paraense Emílio Goeldi. Ciências Humanas, v. 3, n. 2, p. 149, 2008.

ANDERSON, Anthony; POSEY, Darrell. Manejo de cerrado pelos índios Kayapó. Boletim do Museu Paraense Emílio Goeldi, série Botânica, v. 2, n. 1, p. 77-98, 1985. 